\title{
APPLICATION AND COMPARISON OF THREE TOMOGRAPHIC TECHNIQUES FOR DETECTION OF DECAY IN TREES
}

\author{
by G. Nicolotti ${ }^{1}$, L.V. Socco ${ }^{2}$, R. Martinis', A. Godio ${ }^{2}$, and L. Sambuelli ${ }^{2}$
}

\begin{abstract}
This paper reports application of electric, ultrasonic, and georadar tomography for detection of decay in trees and their comparison with the traditional penetrometer. Their feasibility in arboriculture is also evaluated, critically considering some "open problems." The experiments were carried out in an urban environment on two plane (Platanus hybrida Brot.) trees. Both trees, after felling, showed extensive white rot in the central cylinder. The electric tomography revealed low resistivity zones roughly centered in the trunk. A comparison with the successively cut sections showed a fine correspondence to decayed areas and a strong correspondence between high moisture zones and low resistivity zones. Ultrasonic tomography demonstrated to be a very effective tool for the detection of internal decay, accurately locating the position of the anomalies and estimating their size, shape, and characteristic in terms of mechanical properties. With the georadar technique, the high contrast of electromagnetic impedance measured between the inner decayed section and the outside sound section allowed the detection of the interface between the sound and decayed section of the tree, using radar acquisition in reflection modality. The penetrometer profiles detected the low-resistance areas inside the two trunks.
\end{abstract}

Key Words. Tree stability; wood decay; tomography; ultrasound; electric; georadar.

The field guide for the visual tree assessment method (VTA) (Mattheck and Breloer 1994) suggests three different tools for detection and quantification of internal defects in trees: a sound impulse hammer, a penetrometer, and a fractometer. The visual tree inspection and its instrumental approach represented, without any doubt, a qualitative leap compared to the old and simple analysis made with the increment borer; in the meantime, the wide, practical use of VTA supported a strong interest in developing and applying more rapid and precise diagnostic techniques to detect defects in wood.

The methods for noninvasive evaluation analyze physical and chemical properties of wood: density (Beall 1996; Sandoz 1996; Bucur and Rasolofosaon 1998; Bucur 1999), electrical resistivity (Dubbel et al. 1999; Weihs et al. 1999), modulus of elasticity (Bucur 1995; Ross et al. 1997; Berndt et al. 1999), ionic concentration and moisture content
(Zoughi 1990; Smith and Ostrofsky 1993). In recent years, there has been an evolution of the instruments applying the aforementioned techniques (Nicolotti and Miglietta 1998), often developed for engineering or medical applications, such as penetrometers, electrical conductivity meters, ultrasonic detectors, $\mathrm{x}$-rays, and $\boldsymbol{\gamma}$-ray densimeters (Bucur 1985; Adjanohoun et al. 1999; Oja 1999) and nuclear magnetic resonance (Pearce et al. 1997). Most of the instruments designed for the investigation of timber, woody structures, and wood-based materials are known as "noninvasive" even if it would be more appropriate to call them "quasi-noninvasive" because, in many cases, probes, electrodes, transducers, etc. are inserted into the wood. Besides, these instruments provide local information influenced by undefined portions of the material surrounding the sensors. For this reason, when applied on the trunks for wood decay detection, it might be better to take measurements in different points to have more information about the investigated section, even if doing so may take longer.

Not by chance, some of these techniques have been recently developed for tomographic investigation. Tomography (from Greek tomos, slice) allows the reconstruction of a cross section through an object by means of measurements performed on the object surface and measuring energy that passes through the object itself (Worthington 1984; Nolet 1987; Stewart 1991). Different types of energy can supply information about different physical properties of the investigated object: Ultrasonic waves provide information on elastic properties of wood; electric fields and radar frequency electromagnetic waves provide information on conductivity (moisture content and ionic concentration); and $\gamma$-rays and $\mathrm{x}$-rays give information on wood density.

Several studies regard tomographic techniques; most of them are on timber and woody structures. Ultrasonic tomography has been applied by Tomikawa et al. (1990) and Biagi et al. (1994) for investigation of poles and timber and by Comino et al. (2000b) on living trees; Dubbel et al. (1999), Weihs et al. (1999), and Comino et al. (2000a) carried out many experiments of electric tomography on living trees; Rust and Göcke (2000) applied sonic tomography on trees; Temnerud and Oja (1998) and Guddanti and Chang (1998) tested x-ray CT (computed tomography) on logs, and Rust (1999) used it on living Scots pines (Pinus 
sylvestris), while tomodensitometry was applied by $\boldsymbol{\gamma}$-rays on wood by Chambellan et al. (1994).

Fewer applications on living trees are reported, particularly with reference to ultrasonic waves, electromagnetic waves (Miller and Doolittle 1990; Godio et al., 2000), and electric fields. In fact, there are some "open problems" with the noninvasive tomographic approach on trees.

With regard to ultrasonic measurements, the main problems are the coupling of the transducers to the bark, the anisotropy of wood, the signal attenuation that could prevent an accurate travel time reading, and the spatial resolution.

With regard to radar frequency electromagnetic waves, the main problems are the coupling of the antennas to the bark, the difficulty of data interpretation, and the signal attenuation due to its high frequency. Nevertheless, high frequency is necessary for a good spatial resolution.

With regard to the electric fields, the main problems are related to high resistivity of the bark, which could prevent the current flow and a reliable voltage measurement.

This paper reports application of electric, ultrasonic, and georadar tomography for detection of decay in trees and their comparison with the traditional penetrometer. Their feasibility in arboriculture is also evaluated, critically considering all the aforesaid "open problems."

\section{MATERIALS AND METHODS}

The experiments were carried out in an urban environment on two plane trees (Platanus hybrida Brot.) that were going to be cut down. On the two trees, referred to as A and B, both tomographic measurements and penetrometric tests were performed on the trunk sections at 40 and $100 \mathrm{~cm}$, respectively, from ground level. After field tests were performed, the trees were cut down and $30 \mathrm{~cm}$ wood disks, corresponding to the investigated sections, were extracted, put in a plastic bag, and stored in the refrigerator at $5^{\circ} \mathrm{C}$. Within $24 \mathrm{~h}$, all the measurements were repeated on the four wood disks in the laboratory in order to compare the results with those obtained directly on the trees.

From the wood disks, cubic samples $(50 \times 50 \times 50 \mathrm{~mm})$ were later extracted according to the scheme shown in Figure 1 , in order to measure or infer some physical properties, such as moisture content, density, porosity, saturation, mass loss, and dielectric constant, that could be correlated with the data obtained by tomographic and penetrometric field tests.

The aforementioned parameters were measured on fresh wood, and the values obtained were used to reconstruct maps of the parameter distribution within each investigated section.

Porosity, saturation, and dielectric constant were estimated as follows:

Porosity $\Phi=\mathrm{Vva} / \mathrm{Vpf}$

$\mathrm{Vpf}=$ apparent volume of the fresh samples (product of the three dimensions of each fresh sample)

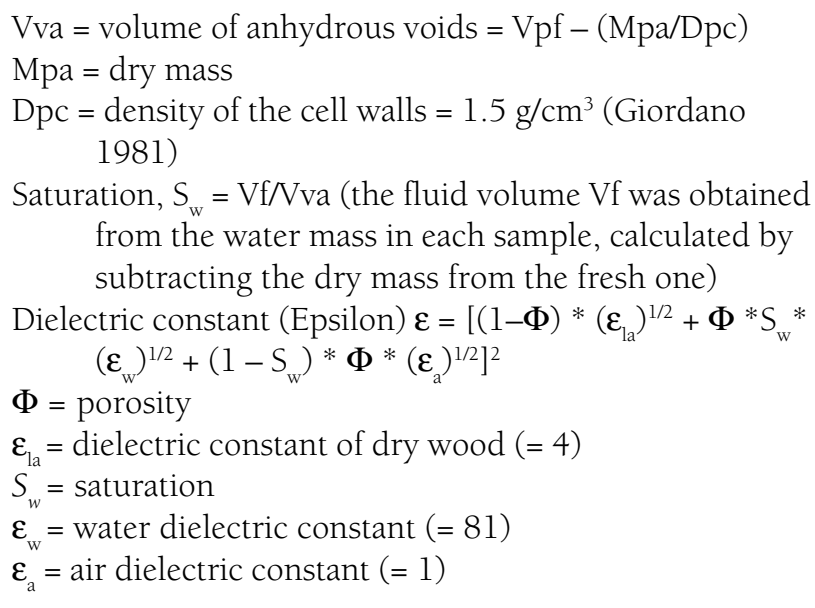

\section{Electric Tomography}

Electric tomography allows the user to obtain an image of the resistivity distribution on a section of a tree. The variation of resistivity values are the result of different types of wood and the changes provoked by the rot decays (Shortle 1982). During the degradation processes, the fungi release a noticeable quantity of ions. Ionization mechanisms are substantially two: Brown rot increases acidity by releasing H-ions, which causes a lowering of wood resistivity; white rot, on the other hand, causes an accumulation of cations and K-ions that, thanks to their high mobility, produce a lowering of the wood resistivity even from the very beginning of the decaying process (Tattar and Shigo 1972; Tattar and Saufley 1973; Shortle and Smith 1987) and an increase of the dielectric constant values (Blanchard and Tattar 1974; Anagnostopoulou-Konsta and Pissis 1988). The resistivity is moreover influenced by wood porosity and texture, which are also modified by the fungi decaying action (Skaar 1988).

Data Acquisition and Processing. Field measurements on the two plane trees were made with a STING R1 georesistivimeter (Advanced Geoscience, Inc., Austin, TX, US). The electrodes were made by $5 \mathrm{~cm}$ long steel nails, laterally coated by an insulating film so that only the tip was electrically conductive.

Sixteen equidistant electrodes (driven to a depth of 1 $\mathrm{cm}$ ) were used with an energizing and reading scheme like the one shown in Figure 2. The use of two diametrically opposite electrodes as current electrodes ensured effective, energizing, and reliable potential readings: current immission between each pair of opposite electrodes and potential reading among all the other electrodes, according to the scheme shown in Figure 2. By the proposed scheme, 96 independent measures were obtained within each wood disk. The collected values of current and potential, together with the geometry of electrodes layout, were then used as input of an inversion software implemented in Matlab ${ }^{\odot}$ and based on a "quasi-Newton" algorithm that was estimated to 


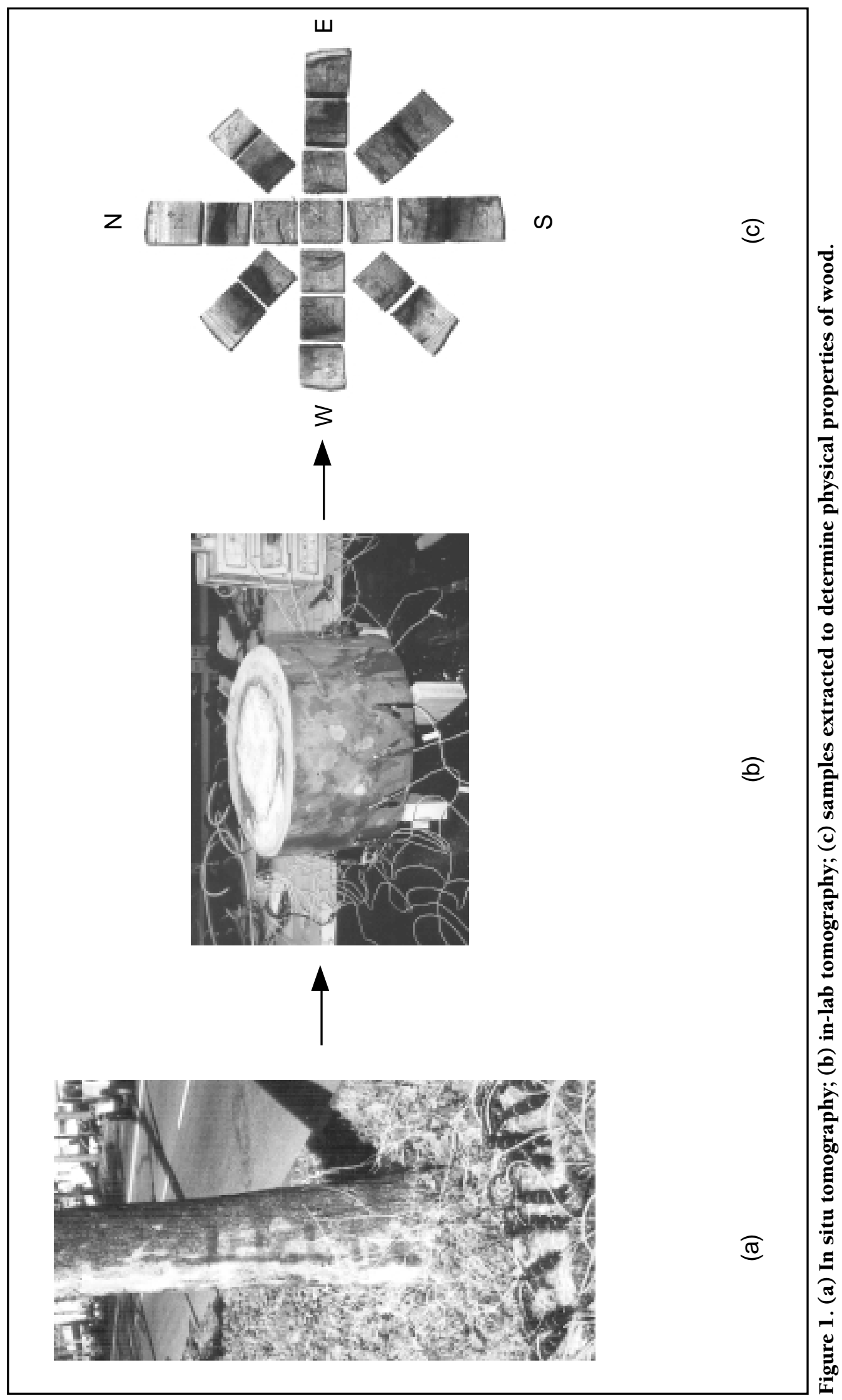


be the most suitable in terms of CPU-time consumption and error propagation (Loke and Barker 1996). As a final result, an adimensional, normalized resistivity map of the trunk section contained in the perimeter described by the electrodes was obtained.

\section{Ultrasonic Tomography}

Ultrasonic tomography allows the user to reconstruct the distribution of the velocity of ultrasonic propagation within the investigated section. Because ultrasonic velocity is related to density and dynamic elasticity modulus, decreasing velocity could be, for instance, diagnostic of fungal degradation of the cell wall (Bucur 1995). Furthermore, ultrasonic velocity has been demonstrated to be very sensitive in the early stage of the wood degradation (Wilcox 1988; Bauer et al. 1991).

Acquisition. The ultrasonic equipment used for data acquisition is a PUNDIT (portable ultrasonic nondestructive digital indicating tester), which is a single-channel device (C.N.S. Electronics, London, UK). An electric signal is transformed, by the transmitter probe, in the ultrasonic pulse that travels through the wood and is received by the receiver probe and transformed again into an electric signal, which can be properly amplified and visualized, allowing for travel time measurements. The probe operating frequency is $33 \mathrm{kHz}$.

The measurements on the trunk were carried out on 16 equidistant points. The transmitter probe was located on point 1 , and the ultrasonic pulse was acquired by the receiver probe in all the other points, then the transmitter was moved to point 2 . The measurements were repeated for all the other positions of the transmitter probe, allowing for 120 independent travel time measurements for each investigated section (Socco et al. 2002). Acquisitions were carried out without barking the wood and by using a coupling gel, which is less invasive than the electric probes. The measuring point coordinates were detected using a simple, specifically designed mechanical gauge. To visualize and record the received signal, the PUNDIT was connected to an oscilloscope and to a portable computer.

Data Processing. The first step in data processing was the travel time reading and improving the reliability of the travel time detection as much as possible. The traces, recorded from the oscilloscope, were filtered to improve the signal-to-noise ratio. After this data processing, a first-arrival picking procedure was performed and a statistical analysis of the time data was carried out. The difficulty in determining the first arrival of the signal in some of the traces acquired emphasized the problem of making ultrasonic

Figure 2. Data acquisition scheme of electric tomography. I: source electrodes; V: receiver electrodes. This picture shows current immission between electrode 1 and 9 and measurement of the potential difference among all other electrodes.

measurements without barking the tree and also serves as a warning about the reliability of some commercial testing devices performing ultrasonic measurements based on autopicking procedures (Berndt et al. 1999).

The travel times and the measuring point coordinates constitute the tomographic processing inputs. The processing was carried out by the software MIGRATOM (USBM), which simulates the ultrasonic pulse propagation as a continuous wavefront, using Fermat's and Huygens' principles. Disregarding the mathematical aspect of the inversion algorithm, the calculation procedure that leads to reconstruction of the velocity distribution within the investigated section can be simply described. The velocity calculation is in fact performed by an SIRT (simultaneous iterative reconstruction technique) starting from a discrete initial arbitrary model of the velocity distribution, then computing the forward model travel times, comparing the calculated travel times with the measured times and, consequently, correcting the initial velocity model. These steps are repeated until the calculated and measured travel times match well enough (until the least squares means between calculated and measured times is reached), and the 
final velocity model is then interpreted in terms of mechanical properties distribution.

The frequency range of ultrasonic signals was chosen in order to obtain an adequate spatial resolution. The signal wavelengths are in fact small enough (a few centimeters) to allow the reconstruction of small details inside the trunk. Furthermore, the knowledge of the input signal supplied by the transducer allows a more reliable analysis of the output signals. On the other hand, the high-frequency signals are more strongly attenuated with respect to low-frequency signals, which could create difficulties in the signal travel time reading. Sonic pulse is often used to overcome these attenuation problems. Energizing with a hammer could supply a sonic pulse propagating into the trunk, and this simple means of energization is commonly used. This approach has two main disadvantages. First, the input signal is unknown; second, and more important, the signal wavelengths are not adequate to the resolution needed and therefore are unable to detect anomalies smaller than some tenths of a centimeter.

\section{Georadar Tomography}

The radar measurements are based on propagation, reflection, and diffractions of impulses at radio frequency, which are sensitive to changes of electrical conductivity and electrical permittivity of the wood. For testing on materials and for very shallow investigation, very high radar wave frequencies are adopted (1,000-1,500 MHz).

Commonly, ground-penetrating radar (GPR) measurements are carried out in single reflection mode using a small dipole antenna; for wood decay detection, a single antenna at 1,500 MHz is employed.

The impulse propagation on the wood depends on the dielectrical properties of bound water, free water, and cell wall components. Therefore, the total porosity and the total water saturation and salinity affect the radiowave propagation.

Energy, associated with wave propagation, is partially reflected in the presence of discontinuities of the water saturation parameter; the travel time and the amplitude of the reflected events are usually determined.

The main goal of radar experiments on the trunk is to evaluate the possibility of obtaining an energy reflection at the boundary between sound wood and decayed wood.

To evaluate the efficiency of radar investigation, we adopted the following approach:

- georadar experiments, in single reflection mode, performed along the perimeter of the two trees

- estimation of electromagnetic behavior of wood, starting from laboratory measurements of some physical properties of the four wood disks (moisture, porosity, density, etc.)

- data processing of georadar image and interpretation and correlation with physical section of the wood
Data Acquisition and Processing. The main experiments discussed here refer to the data acquisition in single reflection mode using a single antenna applied all around the investigated sections, sticking to the trunk, with the main frequency at 1,500 MHz and a georadar system SIR-2, made by G.S.S.I. Acquisitions, repeated at the same investigated sections (40 and $100 \mathrm{~cm}$ from ground level). Also, measurements in transparency modality, using two separate antennas (transmitter and receiver), were performed to estimate the average velocity of radio waves inside the trees.

Horizontal and vertical filtering were applied on raw data for the removal of background noise and to enhance the main events (wave reflection). The filtered data were transformed into polar coordinates to display a radar image for an easier and more realistic comparison with the tree sections.

\section{Electromagnetic Model}

The electromagnetic model allows a user to analyze the changes of electromagnetic behavior between sound and decayed wood. The approach followed moves from the classical complex refractive index model (CRIM) (Birchkak et al. 1984). Similar models are proposed in technical literature to estimate the electrical permittivity of wood, considered as a mixture of cell wall, free water, bound water, and air (Torgovnikov 1993).

The electric permittivity of wood samples can be calculated by the following equation:

$$
\begin{aligned}
& \varepsilon_{\mathrm{m}}=\left[(1-\Phi)^{*}\left(\varepsilon_{\mathrm{p}}\right)^{1 / 2}+\Phi * \mathrm{~S}_{\mathrm{w}}\left(\varepsilon_{\mathrm{w}}\right)^{1 / 2}+\left(1-\mathrm{S}_{\mathrm{w}}\right) * \Phi^{*}\left(\varepsilon_{\mathrm{a}}\right)^{1 / 2}\right]^{2} \\
& \varepsilon_{\mathrm{m}}^{\prime}=\mathcal{E}_{\mathrm{p}}^{\prime}+\mathrm{V}_{\mathrm{w}} *\left(\varepsilon_{\mathrm{w}}^{\prime}-\varepsilon_{\mathrm{b}}^{\prime}\right)=\varepsilon_{\mathrm{p}}^{\prime}+\mathrm{V}_{\mathrm{w}} *\left(\varepsilon_{\mathrm{w}}^{\prime}-1\right) \\
& \mathrm{v}_{\mathrm{w}}=\phi^{*} \mathrm{v}_{\mathrm{T}}
\end{aligned}
$$

where $\mathrm{e}_{m}, \mathrm{e}_{p}, \mathrm{e}_{w}$, and $\mathrm{e}_{a}$ are the dielectric constants, respectively, of fresh wood, dry wood, water, and air; $S_{w}$ is the wood saturation; $\Phi$ is the wood porosity; $V_{T}$ is the total volume; and $V_{w}$ is the water volume (these parameters can be estimated by laboratory measurements of wood in dry conditions).

We consider only the contribution of real part from permittivity, assuming that the electrical conductivity of the single components is negligible. As a reference value for the dielectric parameter of single components, we can assume $\varepsilon_{w}=80\left(\right.$ at $\left.20^{\circ} \mathrm{C}\right), \operatorname{tg} \boldsymbol{\delta}=0.06($ at $1 \mathrm{GHz}), \varepsilon_{w}=4$ and $\boldsymbol{\varepsilon}_{a}^{\prime}=1$.

Starting from this approach and considering the porosity and moisture content values (determined by laboratory measurements on the wood samples), we can estimate the distribution of dielectric permittivity values in the investigated sections. 


\section{Penetrometer}

The tests were carried out by the Resistograph ${ }^{\circledast} 1410$ at the investigated sections. Two measurements were taken on the section at 90 degrees from each other. These measurements were then repeated in the opposite direction, for a total of four measurements per section where all the other three techniques were applied.

Figure $3(b, d)$ shows the drill profiles overlaid to the ultrasonic tomography to facilitate the comparison between the techniques.

\section{RESULTS}

Both trees, after felling, showed extensive white rot in the central cylinder. Isolation and identification demonstrated that the fungal agent was Ganoderma resinaceum Bourdot. Tree A showed, on both the wood disks, a central decay with a simple geometry (Figure 4a), characterized by a homogeneous wood degradation with a high mass loss (53.6 \%) (Table 1). The borders between sound and decayed wood were clearly marked by the compartmentalization barrier. Tree B showed a central decay with a complex geometry (Figure 3c) and a nonhomogeneous degree of wood decomposition (between $22.7 \%$ and $33.4 \%$ of mass loss) on both the wood disks. The moisture content was always significantly higher in the rotted zones than in the sound ones.

The graphs of distribution of the moisture content, density, porosity, and saturation (Figures 4 and 5) were useful for the tomography interpretation, showing a strong correlation with the wood degradation in term of shape and size (Figure 4).

In all four sections, an increase of the moisture content, porosity, and dielectric constant and a decrease of the density and saturation were detected in the decayed zones.

\section{Electric Tomography}

Field Surveys. The tomographies revealed low resistivity zones roughly centered in the trunk (Figure 4). A comparison with the successively cut sections shows a fine correspondence to decayed areas. The current intensity used in field measurements varied from 2 to $5 \mathrm{~mA}$.

Laboratory Surveys. Laboratory tomographies on the same section of the tree gave different images from field (a)
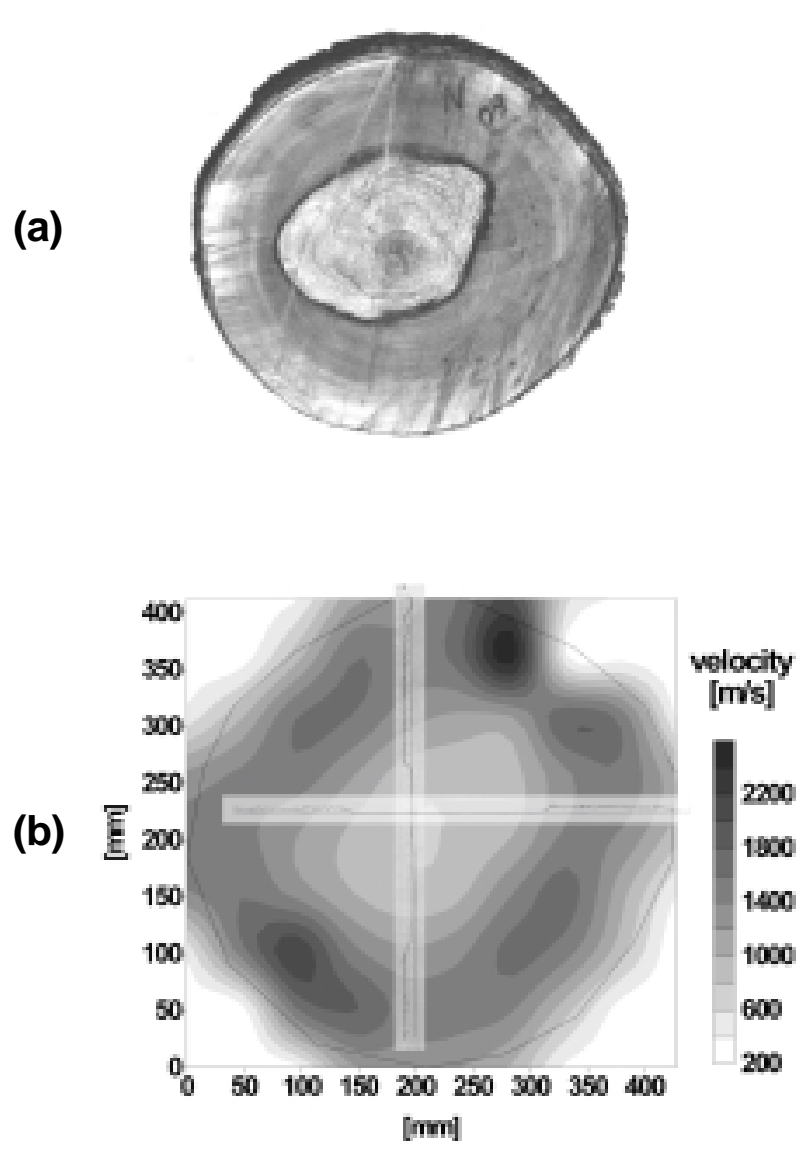

(c)
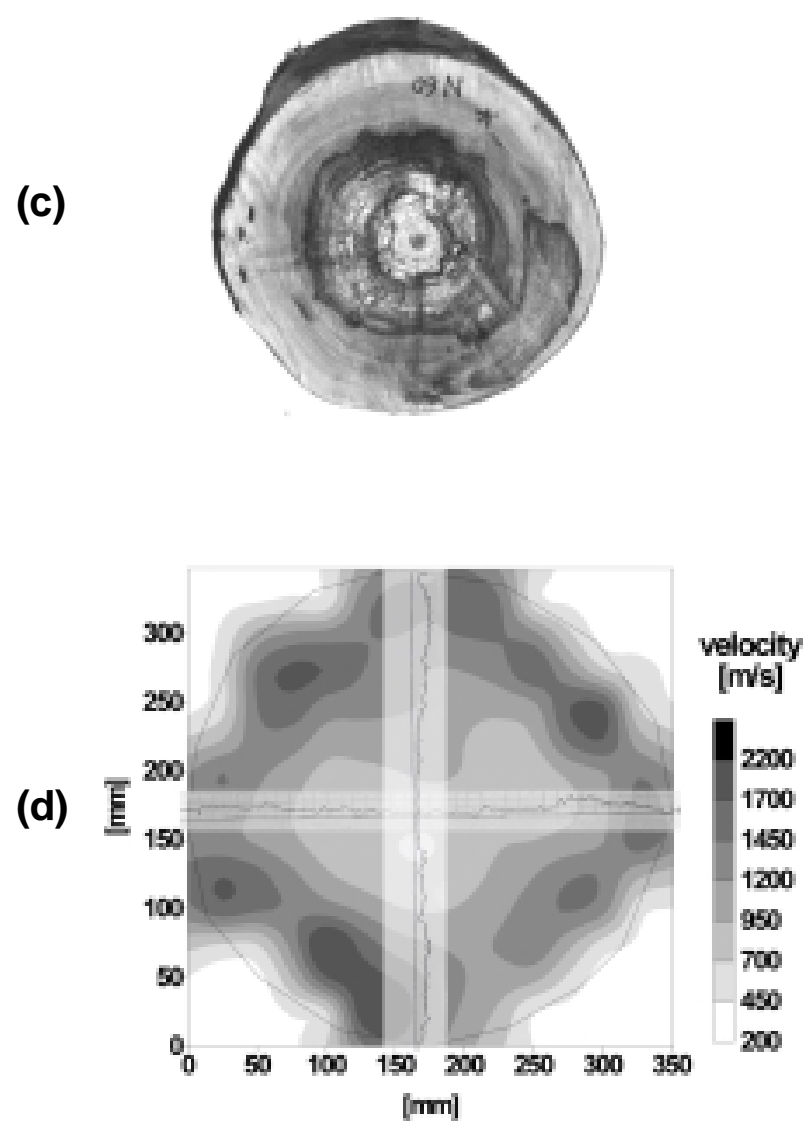

Figure 3. (a) Section of tree $A$ at $100 \mathrm{~cm}$; (b) penetrometer graphs overlaid to the ultrasonic tomography; (c) section of tree $B$ at $100 \mathrm{~cm}$; (d) penetrometer graphs overlaid to the ultrasonic tomography. 


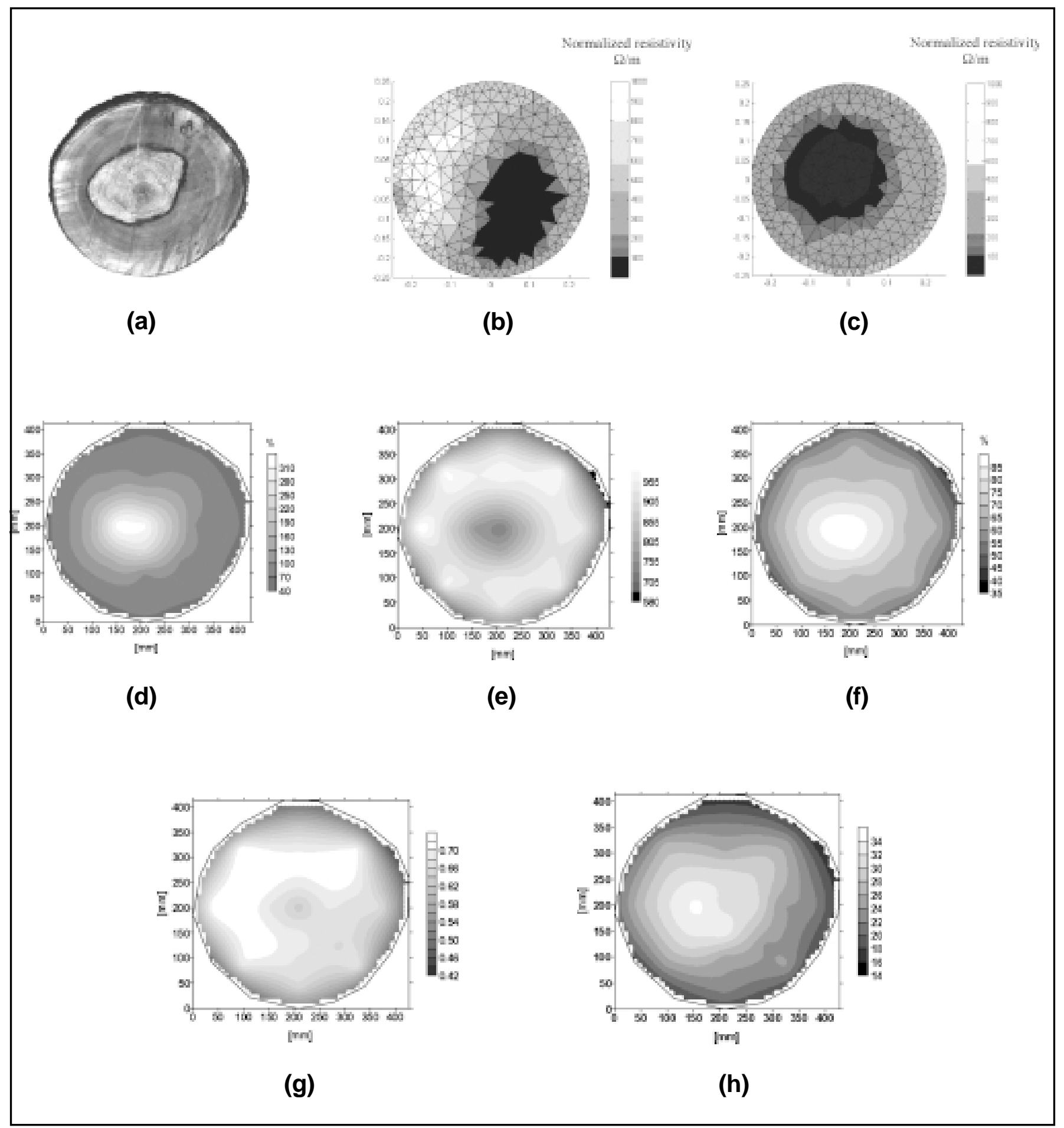

Figure 4. Electrical tomography on tree A at $100 \mathrm{~cm}$ of height: (a) section; (b) in situ tomography; (c) in-lab tomography; (d) distribution of moisture content (MC); (e) distribution of density; (f) distribution of porosity; (g) distribution of saturation; (h) distribution of dielectric constant. 
Table 1. Physical parameters of plane tree wood samples. For each wood disk of each tree, different letters (between sound and decayed samples) show values significantly different for $P<0.01$ (ANOVA Tukey HSD test).

\begin{tabular}{|c|c|c|c|c|}
\hline & Sound wood & Decayed wood & Sound wood & Decayed wood \\
\hline Moisture content (\%) & $91.2 \pm 5.9 \mathrm{a}$ & $321.1 \pm 152.2 b$ & $99.4 \pm 5.7 \mathrm{a}$ & $212.1 \pm 89.0 \mathrm{~b}$ \\
\hline Loss of mass in decayed zone (\%) & \multicolumn{2}{|c|}{$53.6 \pm 21.7 \mathrm{a}$} & \multicolumn{2}{|c|}{$33.4 \pm 22.2 \mathrm{a}$} \\
\hline Wood disks at $100 \mathrm{~cm}$ & \multicolumn{2}{|c|}{ Tree A (diameter: $42 \mathrm{~cm}$ ) } & \multicolumn{2}{|c|}{ Tree B (diameter: $35 \mathrm{~cm}$ ) } \\
\hline Loss of mass in decayed zone (\%) & \multicolumn{2}{|c|}{$39.0 \pm 19.4 \mathrm{a}$} & \multicolumn{2}{|c|}{$22.7 \pm 18.6 \mathrm{a}$} \\
\hline
\end{tabular}

tomographies. These differences are probably due to many factors, among them the different contact impedances of the electrodes when performing in situ and laboratory tests, sometimes preventing the use of a particular measurement. Therefore, anomalous areas (as in Figure 4b) can be generated because of a lack of information.

The strong relationship between resistivity and moisture is demonstrated in Figure 4, where the correspondence between high-moisture zones and low-resistivity zones is evident. Also, according to literature (Torgovnikov 1993), the inverse relationship between resistivity and dielectric permittivity is evident. In the case of tree A, the geometry and the dimension of the decayed area has been well identified and resolved (Figure 4). The current intensity used in lab measurements was kept constant at $5 \mathrm{~mA}$.

\section{Ultrasonic Tomography}

Concerning the detection of rot and decay, the comparison between the results of field and laboratory tomography did not show any significant differences.

Ultrasonic tomography proved to be an effective tool for the detection of internal decay, locating with accuracy the position of the anomalies and estimating their size, shape, and characteristics in terms of mechanical properties

(Figure 3). In all the investigated sections, the zones showing an estimated velocity between 600 and $1,200 \mathrm{~m} / \mathrm{s}$ correspond to the decayed areas, while sound zones showed higher velocities, between 1,200 and more than $2,000 \mathrm{~m} / \mathrm{s}$, in agreement with values reported in the literature for sound wood (Sandoz et al. 2000).

The proposed technique is also sensitive to early stages of decay (Bauer et al. 1991). In tree B, for instance, a decay characterized by a mass loss of only $15 \%$ was clearly detected.

In all the tomographic images obtained, a low-velocity zone extending in the peripheral zone along the perimeter was evident. The cause of this effect is discussed in the conclusion.

\section{Georadar}

Because the permittivity contrast is of primary importance in generating a reflected signal in georadar application, the results depicted in Figure 5 must be analyzed in detail.

With reference to laboratory analysis performed on wood disks, the computed dielectric distribution inside the section is in the range between 10 and 30; the general trend is an increase of dielectric values from the external section to the core of the tree. Particularly, the high values of dielectric are well correlated with the inner decayed core of the two trees. Therefore, we expected a high contrast of electromagnetic impedance between the inner section and the outer section. This justified, from a theoretical point of view, the possibility of detecting the interface between the sound and decayed section of the tree, using radar acquisition in reflection modality.

The radar sections acquired in single reflection mode are represented in polar mode, considering only the time window up to the half time of the travel time inside each tree.

The wavelength in the section was estimated according to the average wave velocity in the section; at the main frequency of $1,500 \mathrm{MHz}$, we estimated a wavelength of about 6 to $8 \mathrm{~cm}$, equivalent to a radial resolution in the radar image of $2 \mathrm{~cm}$.

With reference to Figure 5, two relevant reflected events can be pointed out: A first event, close to the external boundary of the tree, is related to the interface between the external low-saturated zone and the intermediate part of the section; a strong anomaly in the southeast part of the radar image is correlated to lack in the contrast of electromagnetic impedance of the medium between the external and the internal zones. This section is characterized by a gradual change in the electromagnetic properties from the external decayed area and the internal core of the tree. The second main reflected event is related to the interface between the intermediate (high-saturated zone) and the internal core with low saturation values. This event well depicts the decayed core of tree $B$. 


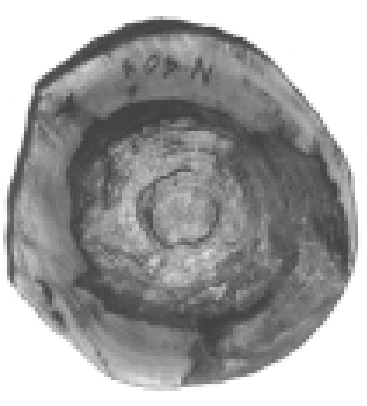

(a)

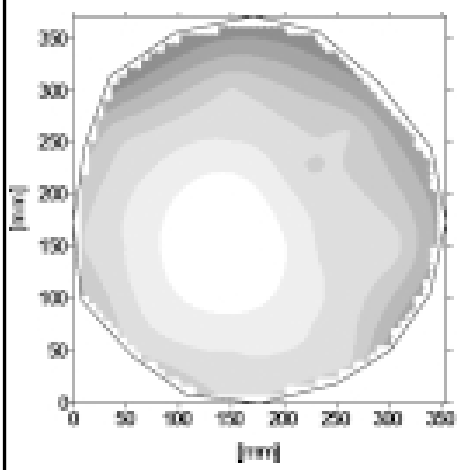

(d)

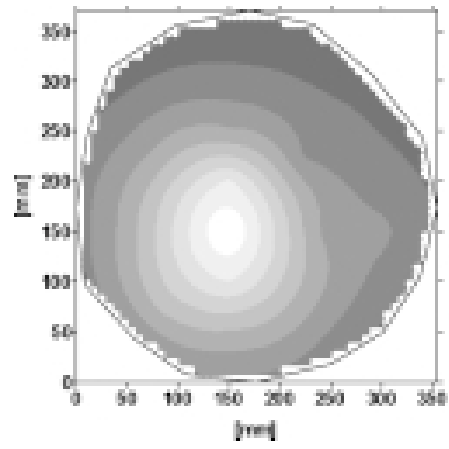

(b)

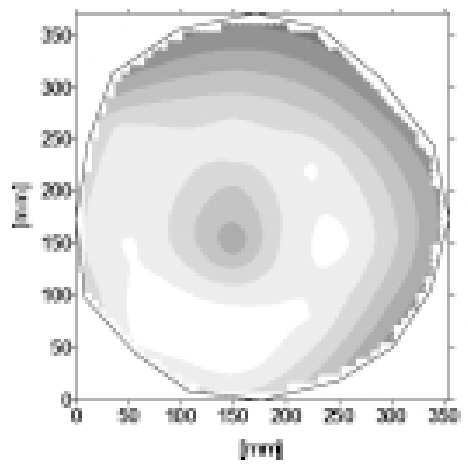

(e)

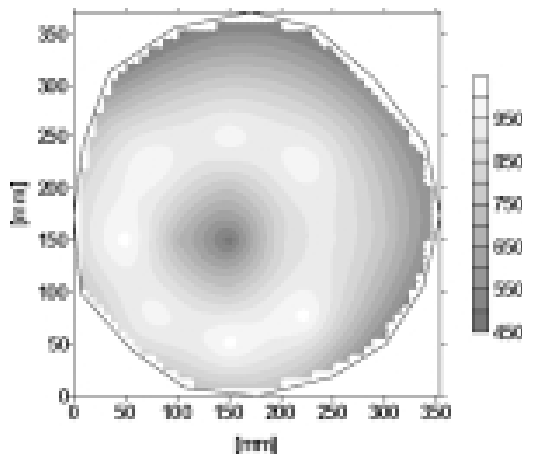

(c)

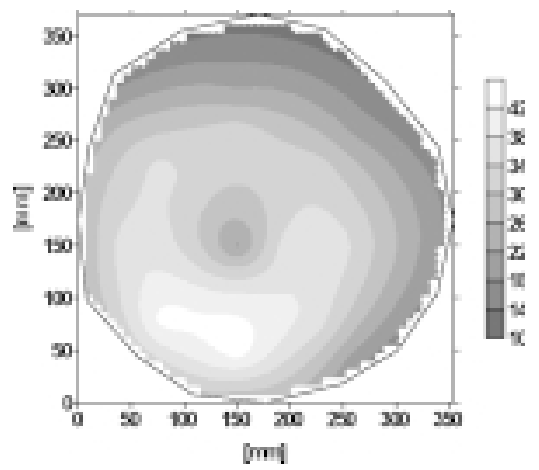

(f)

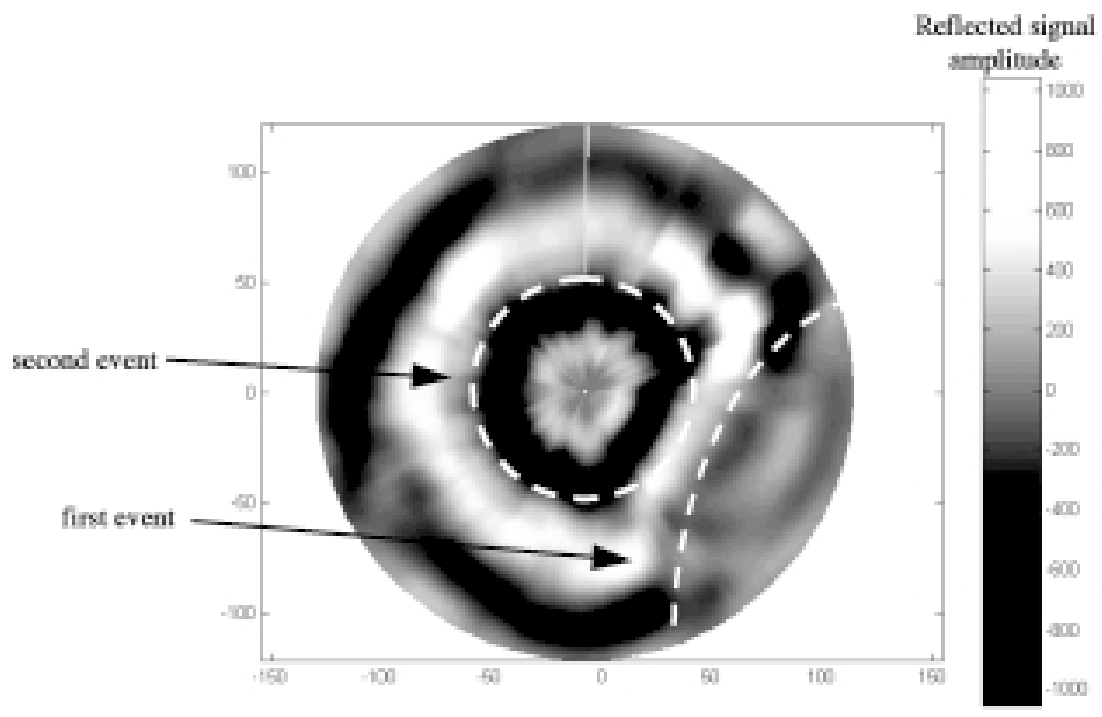

(g)

Figure 5. Tree B, at $40 \mathrm{~cm}$ of height: (a) section; (b) distribution of moisture content (MC); (c) distribution of density; (d) distribution of porosity; (e) distribution of saturation; (f) distribution of dielectric constant; (g) radar image with distribution of amplitude of reflected signal. 


\section{Penetrometer}

Before analyzing the results of this device, we must emphasize that, from the conceptual point of view, it would not be correct to compare the tomographic techniques with the penetrometer because the data they give are different. The tomographic image is the result of dozens of acquisitions on the same section (96 traces for the electric technique and 120 traces for the ultrasonic one); the penetrometer investigation is restricted to the portion of the drill application to the trunk.

The penetrometer test was carried out in this work because, until now, it was the standard method used in the VTA procedure. In any case, the drill profiles detected a lowresistance area inside the two trunks. Particularly in tree A was a good correspondence between the drill profile and the shape of the wood decay (Figure $3 \mathrm{~b}$ ). In the case of tree $\mathrm{B}$, the decayed area, characterized by a low mass loss, was less accurately detected (Figure 3d).

\section{DISCUSSION}

All the investigation techniques proposed have been able to ascertain the presence of internal decay through the detection of physical property variations. Particularly, all these variations were evident in correspondence with the drop of wood density (as in tree A) and the moisture increase (as in tree B).

The best results were from the wood disks showing a high mass loss, a homogeneous degradation, a clear compartmentalization barrier, and decay with a simple geometry.

In the case of the wood disk of tree A (section at 100 $\mathrm{cm}$ ), the wood decay was precisely located by ultrasonic tomography (Figure 3b), by in-lab electric tomography (Figure 4b), and by the penetrometer (Figure 3b).

In the case of tree B (Figure 3c), where the wood disk showed a low wood degradation, a decay with a complex geometry, and a nonhomogeneous status of degradation, the ultrasonic tomography gave the best results, precisely detecting the decayed area (Figure 3d); the other techniques were less precise.

For electric tomography, together with some very good results shown in Figure 4, we still achieved some less reliable ones. The less reliable results were primarily the result of two factors: the use of instruments designed for measuring materials with lower impedance (hardware factor), and a software factor - that is, the first release of the inversion software that considers the trunk as a perfectly round body, which is not always true.

For ultrasonic tomography, a low-velocity peripheral zone is always present on tomographic images. This lowvelocity ring is probably the result of wood anisotropy. In the investigated plan, tangential velocity of ultrasonic pulse (VTT) is lower than velocity in radial direction (VRR) (Bucur 1995). In the radial direction, elastic waves propagate along a high-velocity travel path, represented by the medullary rays. Within the tomographic image reconstruction, the velocity values of the peripheral zone of the section are more influenced by signal propagating in the tangential direction and, therefore, by tangential velocity, while for the velocity estimate for the inner part of the section, radial velocity plays a more important role. Previous studies (Socco et al. 2002) have proved how this can generate a "ghost" effect on the tomographic image if the interpretation algorithm is based on an isotropic modeling.

The ultrasonic tomography is a noninvasive technique, even if sometimes the thick bark may represent a problem for wave propagation because of the signal attenuation and the coupling of the transducer to the bark.

Electric tomography requires the use of electrodes inserted into the wood for not more than 3 or $4 \mathrm{~cm}$, and the penetrometer uses drills and penetrates up to $150 \mathrm{~cm}$. In this case, if the compartmentalization zone is formed, we assume that it is pierced and that this hole will be an entry for fungi (Wessolly 1995).

We are now studying and developing capacitance tomography, measuring the dielectric properties of wood by means of electrode plates to be leaned against the trunk without barking it. This approach gives, as a result, a permittivity distribution showing a good correlation with the wood degradation.

For the described investigation techniques, it is not always possible, at present, to supply a quantitative correlation between the variation of the physical parameter estimated and the effective degree of decay. For instance, considering the results of ultrasonic tomography, the velocity values estimated for the decayed areas are, in the case of tree A (42\% of mass loss) between 600 and 1,000 m/s (Figure 3b), while in the case of tree B ( $21 \%$ of mass loss), the velocity is between 700 and $1,100 \mathrm{~m} / \mathrm{s}$. The estimated velocity value is then diagnostic of the fact that the area is characterized by decay but is not able to discriminate among different degrees of the decay itself. This fact is mainly a result of underestimation of the velocity decrease in the decayed area caused by the fact that ray paths tend to avoid low-velocity regions and, therefore, the corresponding travel times do not contain information on the material within these slow areas. In addition, tomographic processing in general tends to reduce the parameter contrasts, supplying a smoothed image.

The tomography investigations are able to detect small "anomalies" into the trunk. With the ultrasonic technique, the smallest detectable size depends on the frequency: The higher the frequency, the smaller the wave length. In our study, the frequency of $54 \mathrm{kHz}$ allows the detection of anomalies of about $5 \mathrm{~cm}$.

This last aspect has a practical spinoff allowing arborists to detect wood decay at an early stage, which allows them to plan the future management of the tree. 
Moreover, the tomographic approach gives not only information about the decay extension but also provides information about the physical properties of the sound wood (i.e., density and modulus of elasticity).

The lack of user-friendly devices for rapid data acquisition and easy interpretation is, at the moment, the main handicap to be solved. On the other hand, the high potential of the techniques described and the sensitivity and the detail they showed in detecting wood decay at their early stage press us to carry on our research in this direction.

\section{LITERATURE CITED}

Adjanohoun, G., J.L. Guillot, J.D. Lanvin, and R. Cholat. 1999. Small roundwood grading by nondestructive $\mathrm{x}$ rays and ultrasonic waves methods, p 7. In Fifth World Conference on Timber Engineering, Montreaux, Switzerland, 17-20 August 1998.

Anagnostopoulou-Konsta, A., and P. Pissis. 1988. The influence of humidity on the dielectric properties of wood, pp 105-108. In Fifth International Conference on Dielectric Materials, Measurements and Applications, 27-30 June 1988.

Bauer, C., G. Kilbertus, and V. Bucur. 1991. Technique ultrasonore de caractérisation du degré d'altération des bois de hêtre et de pin soumis à l'attaque de differents champignons. Holzforschung 45(1):41-46.

Beall, F.C. 1996. Application of ultrasonic technology to wood and wood-based materials, p 10. In Second International Conference on the Development of Wood Science/Technology and Forestry, Sopron, Hungary.

Berndt, H., A.P. Schniewind, and G.C. Johnson, 1999. Highresolution ultrasonic imaging of wood. Wood Sci. Technol. 33:185-198.

Biagi, E., G. Gatteschi, L. Masotti, and A. Zanini. 1994. Tomografia ad ultrasuoni per la caratterizzazione difettologica del legno. Alta frequenza-Rivista di elettronica 6(2):48-57.

Birchkak, R., C.G. Gardner, J.E. Hipp, and J.M. Victor. 1984. High dielectric constant microwave probes for sensing soil moisture. Proc. IEEE 62:93-98.

Blanchard, R.O., and T.A. Tattar. 1974. Electrical properties of wood in progressive stages of discoloration and decay. Phytopathology 64(5):578-579.

Bucur, V. 1985. Ultrasonics, hardness and X-ray densitometric analysis of wood. Ultrasonics Nov:269-275.

- 1995. Acoustics of Wood. CRC Press Inc., Boca Raton, FL. 286 pp.

- 1999. Acoustics as a tool for the nondestructive testing of wood, p 7. International Symposium on NDT Contribution to the Infrastructure Safety Systems, Torres, Brazil, 22-26 November 1999.

Bucur, V., and P.N.J. Rasolofosaon. 1998. Dynamic elastic and nonlinearity in wood and rock. Ultrasonics 36:813-824.
Chambellan, D., G. Pascal, and P. Reverchon. 1994. Imageur radiometrique pour le controle par défilement ou la tomodensitometrie à l'aide de photons $\mathrm{X}$ ou gamma, pp 67-74. Sixth Conference COFREND, Nice, France.

Comino, E., R. Martinis, G. Nicolotti, L. Sambuelli, and V. Socco. 2000a. Low current tomography for tree stability assessment, p 278. In Backhaus, G.F., H. Balder, and E. Idczak (Eds.). International Symposium on Plant Health in Urban Horticulture, Braunschweig, Germany, 22-25 May 2000.

Comino, E., V. Socco, R. Martinis, G. Nicolotti, and L. Sambuelli. 2000b. Ultrasonic tomography for wood decay diagnosis, p 279. In Backhaus, G.F., H. Balder, and E. Idczak (Eds.). International Symposium on Plant Health in Urban Horticulture, Braunschweig, Germany, 22-25 May 2000.

Dubbel, V.V., U. Weihs, F. Krummheuer, and A. Just. 1999. Neue methode zur zweidimensionalen Darstellung von Fäulen an Fichte. AFZ/DerWald. 26:1422-1424.

Giordano, G. 1981. Tecnologia del legno. La materia prima. Vol. 1, UTET, Torino (I). 1256 pp.

Godio, A., T. Guo, R. Martinis, G. Nicolotti, and L. Sambuelli. 2000. Radar investigation on wood decay and roots, $p$ 280. In Backhaus, G.F., H. Balder, and E. Idczak (Eds.). International Symposium on Plant Health in Urban Horticulture, Braunschweig, Germany, 22-25 May 2000.

Guddanti, S., and S.J. Chang. 1998. Replicating sawmill sawing with topsaw using CT images of a full-length hardwood log. For. Prod. J. 48(1):72-75.

Loke, M.H., and R.D.Barker. 1996. Rapid least square inversion of apparent resistivity pseudosections using quasi-Newton method. Geophys. Prospect. 48:131-152.

Mattheck, C., and H. Breloer. 1994. Field guide for visual tree assessment (VTA). Arboric. J. 18:1-23.

Miller, W.F, and J.A. Doolittle. 1990. The application of ground-penetrating radar to detection of internal defect in standing trees, pp 263-274. Proceedings of the 7th International Nondestructive Testing of Wood Symposium, Madison, WI, 27-29 September 1989.

Nicolotti, G., and P. Miglietta. 1998. Using high-technology instruments to assess defects in trees. J. Arboric. 24(6):297-302.

Nolet, G. 1987. Seismic Tomography, with Applications in Global Seismology and Exploration Geophysics. Reidel, Boston, MA. 336 pp.

Oja, J. 1999. X-ray Measurements of Properties of Saw Logs. Doctoral Thesis, Luleå University of Technology, Skellefteå Campus, Division of Wood Technology. 124 pp.

Pearce, R.B., B.J. Fisher, T.A. Carpenter, and L.D. Hall 1997. Water distribution in fungal lesions in the wood of sycamore (Acer pseudoplatanus), determined gravimetrically and using nuclear magnetic resonance imaging. New Phytol. 135:675-688. 
Ross, R.J., R.C. DeGroot, W.J. Nelson, and P.K. Lebow. 1997. The relationship between stress wave transmission characteristics and the compressive strength of biologically degraded wood. For. Prod. J. 47(5):89-93.

Rust, S. 1999. Comparison of three methods for determining the conductive xylem area of Scots pine (Pinus sylvestris). Forestry 72(2): 103-108.

Rust, S., and L. Göcke. 2000. PICUS sonic tomograph-A new device for nondestructive timber testing, p 300. In Backhaus, G.F., H. Balder, and E. Idczak (Eds.). International Symposium on Plant Health in Urban Horticulture, Braunschweig, Germany, 22-25 May 2000.

Sandoz, J.L. 1996. Ultrasonics solid wood evaluation in industrial applications, pp 147-154. In Tenth International Symposium on Nondestructive Testing of Wood, Lausanne, Switzerland, 26-28 September 1996.

Sandoz, J.L., Y. Benoit, and L. Demay. 2000. Standing tree quality assessments using acousto ultrasonic, pp 172179. In Backhaus, G.F., H. Balder, and E. Idczak (Eds.). International Symposium on Plant Health in Urban Horticulture, Braunschweig, Germany, 22-25 May 2000.

Shortle, W.C. 1982. Decaying Douglas-fir wood: Ionization associated with resistance to a pulsed electric current. Wood Sci. 15(1):29-32.

Shortle, W.C., and K.T. Smith. 1987. Electrical properties and rate of decay in spruce and fir wood. Phytopathology 77(6):811-814.

Skaar, C. 1988. Wood-Water Relations. Springer-Verlag, New York, NY. 279 pp.

Smith, K.T., and W.D. Ostrofsky. 1993. Cambial and internal electrical resistance of red spruce trees in eight diverse stands in the northeastern United States. Can. J. For. Res. 2(2):322-326.

Socco, L.V., L. Sambuelli, R. Martinis, G. Nicolotti, and E. Comino. 2002. Nondestructive ultrasonic tomography for urban forest management to detect hazardous trees. Res. Nondestruct. Eval. (submitted).

Stewart, R.R. 1991. Exploration of Seismic Tomography: Fundamentals. Society of Exploration Geophysicists Course Notes. 190 pp.

Tattar, T.A., and G.C. Saufley. 1973. Comparison of electrical resistance and impedance measurements in wood in progressive stages of discoloration an decay. Can. J. For. Res. 3(4):593-595.

Tattar, T.A., and A.L. Shigo. 1972. Relationship between the degree of resistance to a pulsed electric current and wood in progressive stages of discoloration and decay in living trees. Phytopathology 62(7):792.

Temnerud, E., and J. Oja. 1998. A preliminary study on unbiased volume estimation of resin pockets using stereology to interpret CT-scanned images from one spruce log. Holz Roh Werks. 56:193-200.
Tomikawa, Y., Y. Iwase, K. Arita, and H. Yamada. 1990. Nondestructive inspection of wooden poles using ultrasonic computed tomography. IEEE Trans. UFFC. 33(4):354-358.

Torgovnikov, G. 1993. Dielectric Properties of Wood And Wood-Based Materials. Springer-Verlag, New York, NY. $196 \mathrm{pp}$.

Weihs, U., V. V. Dubbel, F. Krummheuer, and A. Just. 1999.

Die Elektrische Widerstandstomographie-Ein

vielversprechendes Verfahren zur Farbkerndiagnose am stehenden Rotbuchenstamm. Forst Holz. 54 (6): 166170.

Wessoly, L. 1995. Fracture diagnosis of trees. Part 3: Boring is no way for reliable fracture diagnosis. Stadt Gruen. 9: 635-640.

Wilcox, W.W. 1988. Detection of early stages of wood decay with ultrasonic pulse velocity. For. Prod. J. 38(5):68-73.

Worthington, M.H. 1984. An introduction to geophysical tomography. First Break 2:20-26.

Zoughi, R. 1990. Microwave nondestructive testing: Theories and applications. Int. Adv. Nondestruct. Test. 15:225-288.

${ }^{1 *}$ DI.VA.P.R.A. (Dept. for Exploitation and Protection of Agricultural and Forestry Resources)

University of Torino

Via Leonardo da Vinci 44 I-10095 Grugliasco (TO), Italy

giovanni.nicolotti@unito.it

${ }^{2}$ DIGET

Politecnico di Torino

C.so Duca degli Abruzzi, 24 - 10129 Torino, Italy

"Corresponding author: G. Nicolotti. 
Résumé. Cet article traite de l'application de la tomographie électrique, ultrasonique et géoradar pour la détection de la carie dans les arbres et de leur comparaison avec un pénétromètre traditionnel. Leur emploi en arboriculture est aussi évaluée, particulièrement en considérant certains « problèmes ouverts ». Les expériences ont été menées dans un environnement urbain sur deux platanes (Platanus hybrida Brot.). Une fois abattus, les deux arbres présentaient une zone importante de carie blanche dans le cylindre central. La tomographie électrique a révélé des zones de faible résistance approximativement centrées dans le tronc. Une comparaison avec des sections coupées par la suite a démontré une fine correspondance entre les zones cariées et une correspondance forte entre les zones à humidité élevée et celles de faibles résistivité. La tomographie ultrasonique s'est avérée être un outil très effectif pour détecter la carie interne en étant capable de localiser précisément la position des anomalies et d'estimer leur dimension, leur forme et leur caractéristique en termes de propriétés mécaniques. Avec la technique du géoradar, le contraste élevé de l'impédance électromagnétique mesuré entre la section interne cariée et la section externe qui était saine a permis de détecter l'interface entre la section cariée et la section saine de l'arbre, et ce en utilisant l'acquisition radar en modalité de réflexion. Les profils produits par le pénétromètre ont permis de détecter les zones de faibles résistances à l'intérieur des deux troncs.
Resumen. Este informe reporta la aplicación de tomografía eléctrica, ultrasónica y georadar para la detección de la descomposición en árboles y su comparación con el penetrómetro tradicional. Se evaluó también su factibilidad en arboricultura, considerando críticamente algunos "problemas abiertos". Los experimentos fueron llevados a cabo en un ambiente urbano en dos árboles (Platanus hybrida Brot.) Los dos árboles, después de talados, mostraron extensa descomposición en el cilindro central. La tomografía eléctrica reveló baja resistividad aproximadamente en las zonas centrales del tronco. Una comparación con sucesivas secciones mostró una débil correspondencia con áreas descompuestas y una fuerte correspondencia entre zonas de humedad alta y zonas de baja resistividad. La tomografía ultrasónica demostró ser una herramienta muy efectiva para la detección de la descomposición interna, siendo capaz de localizar con precisión la posición de las anomalías y de estimar su forma, tamaño y características en términos de propiedades mecánicas. Con la técnica del georadar, el alto contraste de impedancia electromagnética, medida entre la sección descompuesta interna y la sección sana exterior, permitió la detección de la interfase entre la sección descompuesta y la sección sólida del árbol, usando el radar en la modalidad de reflexión. Los perfiles del penetrómetro detectaron las áreas de baja resistencia dentro de los dos troncos. 